JPBAFM

34,6

46

Received 21 October 2020

Revised 18 February 2021

3 May 2021

10 June 2021

Accepted 14 June 2021

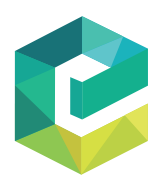

Journal of Public Budgeting, Accounting \& Financial Management

Vol. 34 No. 6, 2022 pp. $46-68$

Emerald Publishing Limited 1096-3367

DOI 10.1108/JPBAFM-10-2020-0177

\section{Balancing between accountability and autonomy: the impact and relevance of public steering mechanisms within higher education}

\author{
Tomi J. Kallio \\ University of Vaasa, Vaasa, Finland and \\ Linnaeus University, Vaxjo, Sweden \\ Kirsi-Mari Kallio \\ University of Turku, Turku, Finland and \\ Department of Accounting and Logistics, Linnaeus University, Vaxjo, Sweden \\ Mira Huusko \\ Finnish Education Evaluation Centre, Helsinki, Finland \\ Riitta Pyykkö \\ University of Turku, Turku, Finland, and \\ Jussi Kivistö \\ Faculty of Management and Business, Tampere University, Tampere, Finland
}

(C) Tomi J. Kallio, Kirsi-Mari Kallio, Mira Huusko, Riitta Pyykkö and Jussi Kivistö. Published by Emerald Publishing Limited. This article is published under the Creative Commons Attribution (CC BY 4.0) licence. Anyone may reproduce, distribute, translate and create derivative works of this article (for both commercial and non-commercial purposes), subject to full attribution to the original publication and authors. The full terms of this licence may be seen at http://creativecommons.org/licences/by/4.0/ legalcode

The authors would like to thank FINEEC for providing the data for this study. 
they also endanger institutional autonomy. In this sense, it could be expected that steering mechanisms should better balance accountability and autonomy.

Keywords Higher education development, Steering mechanisms, Paradox theory, Institutional complexity, Public funding, Universities

Paper type Research paper
Balancing between accountability and autonomy

\section{Introduction}

Over the past few decades, several countries that have traditionally relied on the state-led coordination of higher education have been increasingly developing their steering mechanisms to better correspond with the goals of the changing higher education field (e.g. Enders et al., 2013; Ferlie et al., 2009). While the funding of higher education institutions (HEIs) in these countries is typically provided largely by the tax revenues, the allocation of funding as such is increasingly based on the mimicking of market coordination (e.g. Brown, 2010; Marginson, 2013). The abovementioned redesign of public coordination has affected most of the Western world.

The reasons for redeveloping the public coordination of higher education are numerous and country-specific. However, in global terms, there are also megatrends that have had an indisputable effect in this phenomenon. Perhaps the most evident of these include the global spread of the New Public Management doctrine (Hood, 1995; Miller et al., 1998; Pollitt and Bouckaert, 2004; Vakkuri, 2010); the growing public interest in international rankings and their effect on HEIs' competition for status, students and faculty (Czarniawska, 2019; Gebreiter and Hidayah, 2019; Mingers and Willmott, 2013; Northcott and Linacre, 2010; Pidd and Broadbent, 2015; Shore, 2008; Tourish et al., 2017; Tourish and Willmott, 2015); the growing importance of national and international accreditations (Ahrens and Khalifa, 2015; Alvesson et al., 2017; Czarniawska, 2019; Dobija et al., 2019); and increasing demands for transparency and accountability in higher education (e.g. Kivistö et al., 2019; Pinheiro et al., 2019). Moreover, one should not overlook the effect of public sector isomorphism, or in simpler terms, the tendency of public sector organizations to mimic each other and to copy practices from other sectors and countries (Kallio et al., 2020). All the abovementioned trends affecting the redevelopment of the public coordination of higher education are mutually interconnected and make studying the steering of HEIs a prominent research agenda.

These trends also force most of the HEIs, especially the publicly funded ones, to heed accountability to the state much more than previously (Agyemang and Broadbent, 2015). In the Finnish context, Kallio et al. (2020) recently described the tension emerging from the fact that the state expects universities to develop their strategic planning while their funding scheme is simultaneously so strictly tied to public steering mechanisms that strategic management is impossible. This interpretation is backed up by further evidence of several national-level studies and evaluations. In particular, in the national "Impact Evaluation of the Universities Act Reform” (see Owal Group, 2016), it was concluded that the funding scheme, its indicators and its weight in determining the levels of universities' funding were considered too detailed, thereby constraining the universities' ability in setting their goals. This assumption is further reinforced by the findings from the 2015 evaluation of the Finnish higher education system and the Organisation for Economic Co-operation and Development's (OECD's) review of the Finnish innovation policy in 2017 (Melin et al., 2015; OECD, 2017). Nevertheless, while this tension has been reported in previous studies, the question of why the steering mechanisms are causing tension has not been explicitly studied. The steering mechanisms of HEIs stem mainly from a managerialist background, creating paradoxes of governance in HEIs (Kallio et al., 2021). In this study, we apply the lenses of institutional complexity and paradox theory (Schad et al., 2016) to recognize and study the tensions within 
JPBAFM 34,6

\section{8}

the steering mechanisms. Instead of trying to resolve the tensions, paradox theory deals with the different ways to cope with the competing demands (Smith and Tracey, 2016).

It is the abovementioned tension that is the focus of this article. Thus, there are three objectives for the article, as follows:

(1) To highlight the steering mechanisms applied in coordinating Finnish HEIs as well as to report their experienced impact and relevance.

(2) To gain understanding of why the applied steering mechanisms cause tension for the management of HEIs.

(3) To provide further practical insight into how to develop the public steering of universities based on the previous two objectives.

In our analysis, we focus particularly on the fields of business and economics, engineering, the humanities and social sciences. The results of the empirical findings are viewed from the theoretical frameworks of the paradox theory (e.g. Fairhurst et al., 2016; Schad et al., 2016) and institutional complexity (e.g. Greenwood et al., 2011). By using the two mentioned frameworks in tandem, we aim to achieve rich, generative theorizing to better address the key challenges highlighted.

The article centers on education provided by Finnish universities and touches on universities' research activities only implicitly. The article is based on unique data collected by the Finnish Education Evaluation Centre (FINEEC) in 2019 as part of its extensive external evaluation of the four fields. Bearing in mind the obvious limitations caused by the fact that higher education systems and their respective steering mechanisms differ between countries, the results of this study can be useful beyond the Finnish context when assessing, designing and developing steering mechanisms to coordinate higher education organizations. The results of this study can be extended to cover other contexts that are structurally similar with the system-level coordination of Finnish universities, that is, especially those countries that are applying a mixture of performance-based funding and performance contracts in university funding and hold a strong regulative position of the degree-awarding rights of the universities (cf. Ahonen and Koljonen, 2020). In Europe, this means not just the most obvious cases, such as the other Nordic countries (Pinheiro et al., 2019), but also several other countries (see, e.g. de Boer et al., 2015; Claeys-Kulik and Estermann, 2015; Bennetot-Pruvot and Estermann, 2017). Moreover, the results can be comparatively examined together with other countries sharing sufficient similarities. In addition to the findings related to the steering of HEIs and their policy goals, our study also has relevance for the theoretical analyses of public sector institutions' autonomy contrasted to their accountability pressures as well as the competing and even paradoxical institutional logics (de Boer et al., 2015; Grossi et al., 2020; Kallio et al., 2020; Modell, 2019; Verhoest et al., 2004). With these insights, we participate in the expanding literature on institutional complexity and paradoxes within the public sector domain (Schad et al., 2016; Smith and Tracey, 2016).

\section{Background}

\subsection{Steering of higher education}

The management and governance of HEIs have proven to be a prominent research agenda for over a decade. In higher education, steering can be defined as those "externally derived instruments and institutional arrangements which seek to govern organisational and academic behaviours" within HEIs (Ferlie et al., 2009, p. 2). Broadbent (2007) emphasizes that the steering of HEIs is an interplay between their organizations and their regulatory and financial frameworks. Even though she suggests that a loosely coupled performance 
measurement $(\mathrm{PM})$ system is a way to manage universities, we have witnessed HEIs adopting increasingly more fine-grained and strict PM practices to enable the auditing of the efficiency and quality of operations (Agyemang and Broadbent, 2015).

In recent years, various studies have reported on these PM practices and the ways that HEIs have implemented them (Kallio and Kallio, 2014; Kallio et al., 2016, 2017; ter Bogt and Scapens, 2012). ter Bogt and Scapens (2012) note that the external standardization of the criteria for excellence has become increasingly central in HEIs today. However, the institutionalization of these new models is not complete in many cases, and different types of critique and resistance have been shown (Boitier and Rivière, 2013; Siltaloppi et al., 2019). Some authors have argued that such quantified evaluation criteria result in the overvalorization of quantity over quality (Kallio et al., 2017) or that evaluations become constrained by standardized scores based on rankings and ratings (Lane, 2010). These developments also challenge the traditional collegial view of universities. Something that Craig et al. (2014, p. 2) call the "mania for constant assessment" is challenging the traditional and collegial visions of a university with managerial power and its legitimation. In many cases, the commercial values are changing the universities' governance, accountability, decision-making and communication (Parker, 2002; Parker and Guthrie, 2010). In addition, the rapidly expanding implementation of rankings, accreditations, quality assurance and frameworks for excellence is affecting the steering of HEIs (Grossi et al., 2019; see also Guthrie and Neumann, 2007; Parker and Guthrie, 2010).

Finland has experienced the same type of development, as will be explained in the following sections. Internationally, the adoption of the HEI steering mechanisms in Finland has been one result of a modernization trend that has touched most higher education systems in Western countries (e.g. Kallio et al., 2017, 2020; Kivistö et al., 2017; Suomi et al., 2014; Pinheiro et al., 2019; Iacuzzi et al., 2020). More recently, this trend has also expanded into the East, the Middle East and Africa (e.g. Harun et al., 2020; Komutputipong and Keerasuntonpong, 2019; Upping and Oliver, 2012; Mah'd, 2020; Mkasiwa, 2020).

\subsection{Institutional complexity and paradox theory as lenses to understand opposing demands in the steering of HEIs}

As suggested above, Finnish HEIs struggle with conflicting demands. In their analysis, Smith and Tracey (2016) identify two theoretical frameworks, namely institutional complexity and paradox theory, which have been widely applied by scholars for understanding such a situation. These two theoretical frameworks have been developing mostly independently and have certain differences in the way that they see the source and the nature as well as the challenges and responses with respect to competing demands (Smith and Tracey, 2016).

According to Greenwood et al. (2011), organizations face institutional complexity when there are two or more competing institutional logics affecting them - a situation in which the Finnish HEIs find themselves. There is an array of ways to describe and label the competing logics in academia, such as academic logic and market logic (Juusola et al., 2015), professional and market-oriented logic (Mampaey and Huisman, 2015), managerialism and professionalism (Chandler, 2008; Pettersen, 2015) or even institutional and business bubble perspectives (Alajoutsijärvi et al., 2014). While there may be even more competing logics involved - mainly because Finnish universities are increasingly collaborating with and receiving funding from multiple stakeholders - in this study, we focus on the three competing logics: two distinct variants of state logic, labeled here as constitutional logic and quasimarket logic, as well as professional logic.

In Finland, the higher education field is highly regulated by the state, and the state logic thus plays an important role in the organizational field (Thornton et al., 2012). While the state has lately pursued increasing the autonomy of universities, there are still strict regulations

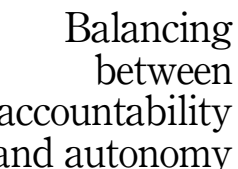

\section{and autonomy}


JPBAFM 34,6 that define - in nuanced ways - numerous issues ranging from the organizational configurations and administrative structures of the universities to their right to provide education (Kallio et al., 2020; see also Karran, 2009; Piiroinen, 2013). Nevertheless, even though state logic is significant in the Finnish HEI sector, the scientific independence and academic freedom of universities and individual scholars have traditionally been perceived as highly important principles in the country (Aarrevaara, 2010). As a manifestation of this importance, these principles have been written into the constitution of the country: "The freedom of science, the arts, and higher education is guaranteed" (Constitution of Finland, section 16). This type of state logic can be labeled as constitutional logic to distinguish it from another type of state logic - quasi-marked logic - affecting the Finnish HEIs.

In the Finnish higher education field, the demands with respect to market logic originate mostly from the Finnish Ministry of Education and Culture (MEC). The MEC applies six steering mechanisms, of which four are tied to funding, as we shall show in more detail in the following sections. Given the situation, the second logic affecting HEIs can be labeled as quasi-market logic (Feiock, 2002; Exworthy et al., 1999) since it is dictated by the state and thus instead of being actual marked logic, it is in fact a variant of state logic. The demand for public sector organizations to mimic the private sector service provision resulting in creating quasi-markets for higher education is increasingly common in those countries in which universities are not typically private-owned, students do not have to pay tuition and the funding for universities is mostly provided by the tax revenues (e.g. Brown, 2010; Marginson, 2013). In Finland and in other Nordic countries, the dominant quasi-market element is more the performance competition between HEIs than the "customer-orientation" and "consumer demand" reflecting quality differences (see Verhoest et al., 2004). As described by Verhoest et al. (2004), even if a university has full decision-making competencies for its management and policy, government influences the actual decisions since the universities depend on the government for a substantial part of their funding. Thus, the actual capacity of universities to use their decision-making power is severely constrained.

The third logic affecting the Finnish HEIs is professional logic (Thornton et al., 2012). Professional logic is an important constituent of the Finnish higher education system and manifested, among others, by the fact that universities' autonomy is guaranteed in the Universities Act (Kallio et al., 2020). Even if the individual professors in Finland might not possess as much power as their colleagues, for instance, in Italy or Germany, Finnish scholars are nevertheless active in making demands and ready to protest if they feel that their scientific independence and academic freedom are being jeopardized (e.g. Kallio et al., 2020; Siekkinen et al., 2020).

When logics are incompatible or competing, they generate challenges and tensions for the organizations exposed to them (Greenwood et al., 2011). Many of the major tensions and change dynamics observed in modern organizations and organizational fields can be examined by considering the struggle among the various actors entangled in contrasting institutional logics, such as the state and the universities. Reay and Hinings (2005) note that competing logics can coexist in tension over an extended period, and one dominant logic can emerge - but only temporarily. Battilana and Lee (2014) state that the different institutional logics can be combined in a more robust way and create hybrid models. In this vein, Pache and Santos (2013) note that hybrid organizations are typically those exposed to multiple institutional logics for a lengthy period of time and that the logics they embody are not always compatible (see also Kallio et al., 2021).

While the situation in which organizations face competing demands is in general considered to be challenging, the theory of institutional complexity accepts the idea that multiple logics can coexist more than just temporarily and that the logics may be complementary; thus, they do not always need to be mutually contradictory (Smith and Tracey, 2016; Besharow and Smith, 2014). Paradox theory, however, takes this idea even 
further and sees that competing demands are inherent in organizations and organizational systems. Schad et al. (2016) define paradox as a "persistent contradiction between interdependent elements."

Rather than trying to resolve them, paradox theory pursues finding ways to cope with the competing demands and potentially even develop positive outcomes, such as creativity and sustainability (Smith and Tracey, 2016). According to Smith and Tracey (2016, pp. 458-459), "paradoxes emphasize a persistent, underlying relationship between opposing forces that cannot be resolved, but must be accepted and accommodated." The authors continue by providing some simple, useful examples of this kind of tension in organizations, such as "today and tomorrow" and "individuals and collectives," where the very endeavors of trying to resolve the opposite would hardly make sense. Nevertheless, paradox theory also accepts the fact that tensions are not always synergistic but can be contradictory and dysfunctional in organizations (Smith and Tracey, 2016).

Smith and Tracey (2016, p. 455) conclude their analysis by stating that the two frameworks - institutional complexity and paradox theory - can be used in tandem and that "drawing from both of these lenses will result in rich, generative theorizing to better address key challenges in the world." In this study, we follow this idea set forth by Smith and Tracey (2016) and apply the two theoretical frameworks as lenses while conceptualizing our empirical findings to highlight the tension between accountability and autonomy - a characteristic in the steering of HEIs in many Western countries.

\section{Empirical context, data collection and analysis}

\subsection{The context of the study: characteristics of the Finnish higher education system}

The higher education system in Finland consists of two separate sectors, universities and universities of applied sciences (Pirttilä et al., 2020; Pyykkö et al., 2020b; Seppälä et al., 2020; Wallenius et al., 2020). This article focuses on universities. After several mergers, there are currently 13 universities in Finland. Finland has a strong tradition of being a Nordic welfare state, which has affected the relationship between the state and HEIs. The Finnish higher education sector has undergone a series of significant reforms during the last decade aimed to enhance the autonomy and accountability of HEIs. The most significant of these reforms was the renewal of university legislation in 2010. Despite these reforms, Finnish HEIs are statedependent for their funding, and the MEC continues to be the most influential stakeholder for HEIs. The MEC has the authority to regulate the number of HEIs as well as the structures and names of the degrees. Moreover, the MEC steers the fields of education and sets targets for degrees granted per institution. Quality assurance in Finnish higher education is based on institutional audits, typically carried out by the FINEEC. Finland does not have programlevel accreditation for educational programs. The overall mode of quality assurance is enhancement-oriented rather than accountability-oriented, and the audits do not lead to any formal sanctions, such as reductions in state financing or rights to offer degrees. Universities have the right to grant degrees in their respective fields of education as defined in a statute by the Finnish Government (Pekkola and Kivistö, 2019a).

No tuition fees are applied to domestic or EU/EEC students, but students outside of the ETA countries pay fees in bachelor's and master's programs. Because no tuition fees are charged, around $92 \%$ of the funding for Finnish universities comes from domestic public sources (OECD, 2019). Of this, the share of the MEC's funding, also called basic funding, is approximately $60 \%$. This basic funding is allocated via a strict performance-oriented scheme (Figure 1).

The MEC's funding scheme is designed to incentivize universities to operate in a way that maximizes the number of degrees and pushes students to faster graduation. In addition, to a lesser extent, the scheme rewards universities for increasing the employability of students and for increasing student satisfaction (student feedback). The research part of the scheme

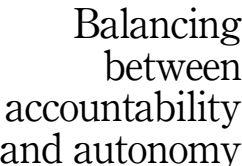


JPBAFM

34,6

52

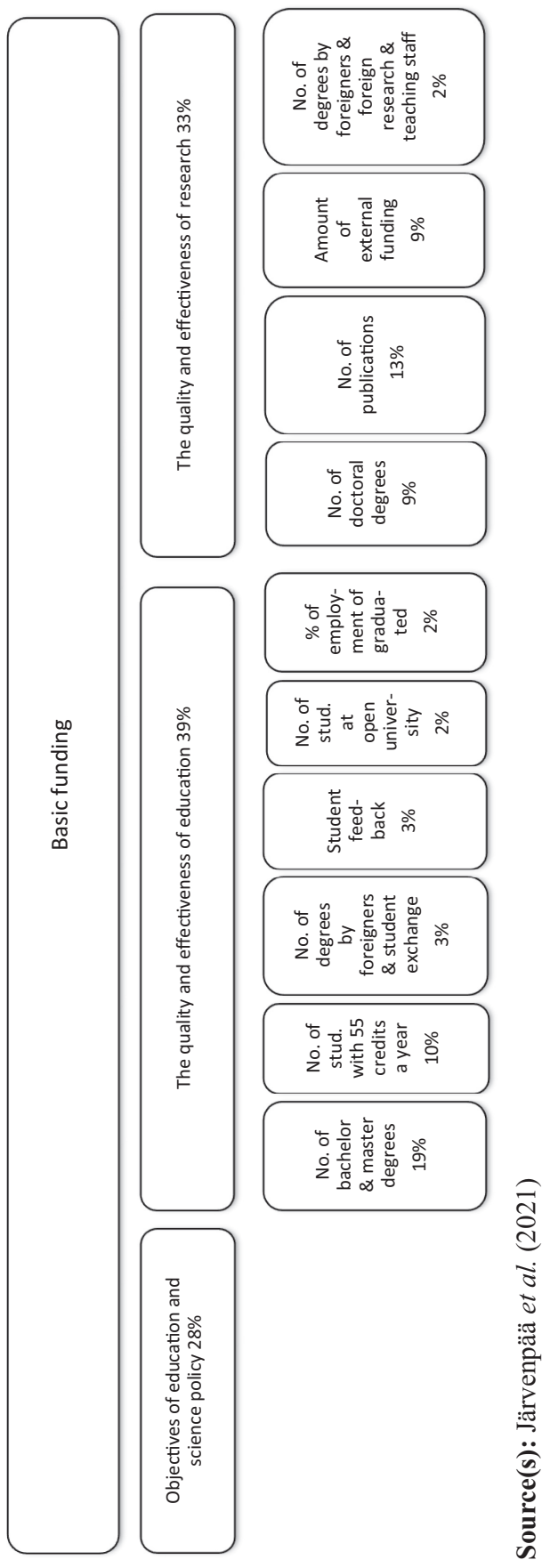

Figure 1.

Formula of basic funding for 
encourages researchers to publish in (highly ranked) international scientific journals. As such, the allocation of basic funding in Finland is among the most performance-driven of the EU countries (Kallunki et al., 2019).

\subsection{The national steering of Finnish HEIs}

In Finland, the activities of HEIs are based not only on the wide autonomy regarding academic issues guaranteed by the Finnish Constitution but also on a continuous and active interaction with the MEC. Consequently, the MEC devises the policy outlines, prepares the regulations and allocates the state funding (MEC, 2021). Formally, state funding covers the education and research activities of the universities, but in practice, for research, the universities have to find financing from other sources (external funding), such as the Academy of Finland, the EU and private foundations and corporations. All external research funding is based on competition. However, competitive research funding is also one of the funding indicators in the state model - making it a part of the steering scheme.

At the start of each four-year agreement period, each HEI and the MEC have negotiations on the objectives for the higher education system, key measures for each HEI, strategic funding and degree objectives, among others. The agreements also specify how the outcomes of the agreed objectives are reported (Pekkola and Kivistö, 2019b). Next, we introduce the six steering mechanisms applied by the MEC, which are indicator-based funding, performance agreements between the MEC and universities, strategy-based funding, project funding, the regulation of the educational responsibility of the universities and steering by information. Out of these six steering mechanisms, the first four are tied to funding, as explained below.

The indicator-based funding (1) allocated by the MEC to the universities is founded on a performance-based funding scheme (Figure 1). Most of the indicator data for the funding model are delivered automatically on a daily basis from the university data warehouses to the national statistical service, Vipunen, maintained by the MEC and the Finnish National Agency for Education (Vipunen, 2020). Funding is allocated as a single entity, and the universities then independently decide on its internal allocation. The total amount of state funding for universities is defined annually in the state budget.

Performance agreements between the MEC and universities (2) play an important role in governmental steering in the Finnish higher education system. In the agreements, the MEC and the universities agree on the following important areas for the four-year period: (1) the objectives set for the higher education system as a whole; (2) the mission, profile and focus areas of the HEI; (3) the key development measures linked to the implementation of the higher education strategy; and (4) funding (indicator-based funding, strategy-based funding, project funding and funding for specific national duties) (de Boer et al., 2015; MEC, 2021). Even though performance agreements overlap with other steering mechanisms related to funding, they have a distinct role in clarifying the profile of each institution and in assigning strategic and specific national tasks to particular universities. de Boer et al. (2015) have suggested that performance agreements stress the resource dependency of universities and limit their room for making choices.

The basis for strategy-based funding (3) has been less transparent in comparison to the two abovementioned steering mechanisms, where the amount has been agreed on in the negotiations between the ministry and each university (MEC, 2021). Strategy-based funding is based on the universities' proposals, on one hand, and the national strategic goals defined by the MEC, on the other. From 2021 onward, the funding will be divided into two parts, as follows: two-thirds of the strategic funding will be based on the strategic goals of each university and one-third on the national goals.

The MEC also uses project funding (4) as a steering mechanism. Project funding can be used for different purposes, but most often it is allocated to the implementation of the national
Balancing between accountability and autonomy 
JPBAFM 34,6

\section{4}

higher education strategy. For instance, the national implementation of the Bologna process has been supported by quite generous state project funding. The initiative for these projects has come from the MEC, but the practical implementation has been in the hands of the universities. As another example, from 2016 to 2020, 65m euros were allocated for so-called Government Key Projects for developing university teaching and learning, especially the digitalization of teaching and learning. There has also been project funding for the development of education in the fields lacking a labor force and for lifelong learning. As these examples show, project funding is used as a clear steering instrument, placing pressure on the HEIs to support the national policy aims (MEC, 2019; Pyykkö et al., 2019).

The regulation of the educational responsibility of the universities (5) is implemented according to by the Universities' Act and the Decree on University Degrees. Provisions on the degrees conferred by each university are given by governmental decree (Government Decree on University Degrees 794/2004) and more explicitly by decree of the MEC (Decree of the MEC clarifying the educational responsibilities of universities 1451/2014), which is prepared in collaboration with the universities. The universities can decide on the establishment of new programs in the field of their responsibility (e.g. educational responsibility in history allows starting new specified programs in cultural history or Finnish history), but if they want to widen the responsibility or stop offering a certain program under their responsibility, they have to propose it to the MEC. Questions of educational responsibilities are in the interests of not only the universities but also the regions and the labor market and are thus highly political.

The ministry also uses steering by information (6), where different data play an important role. Reliable and openly available statistics on higher education have been a part of the Finnish education policy since the 1980s. Each year, each institution receives statistical data on their rating in regard to other Finnish HEIs. All these data are used for the steering, followup and development of higher education. Part of it also has a connection to university funding. Online statistical data are openly available on the webpages of the MEC, the Education Statistics Finland database (Vipunen), Statistics Finland and the Academy of Finland.

\subsection{Empirical material and data analysis}

The empirical data of this study were collected by the FINEEC in 2019 as part of its external evaluation of higher education in business and economics, engineering, the humanities and social sciences. The aim of these field-specific evaluations was to go deeper into the development needs of separate fields of education, which was not deemed possible in the quality audits of HEIs. The evaluations were carried out by four external evaluation teams consisting mainly of Finnish members. The evaluation teams comprised members of upper management (vice-rectors and deans), professors and other teaching personnel and students of HEIs as well as working-life representatives. Evaluations conducted by the FINEEC are implemented according to the principles of enhancement-led evaluation (Pyykkö et al., 2020a).

The evaluation teams formulated a self-assessment questionnaire common to all four fields of education. The self-assessment survey was tested by four representatives of different Finnish universities in February 2019, and the final survey was modified based on the responses. The respondent teams completed the survey in March 2019. The data are unique in that the survey was answered by teams of at least three people representing the universities targeted. In addition, the response rate was exceptionally high at $94 \%$.

The objective of the survey was to form an overall picture of how various factors impact the development of the provision of education at HEIs and how impactful and purposeful the different steering mechanisms are for the development of the education provision. The steering of the higher education system is the focus of this article. 
A total of 33 field-specific small groups from 12 Finnish universities (7-10 per field, Table 1) were asked about the impact and relevance of the different steering mechanisms on the development of education provision [1]. The field-specific small groups included those responsible for the degree program; those responsible for continued learning; students, teaching and research staff; and administrative and support staff. One response per university and field of education was requested for each field examined. In total, 31 responses of the possible maximum of 33 were received [2]. Table 1 presents these data in terms of fields of study. The fact that only three of the 12 universities provide education within all the four fields of science makes the comparison of findings between different universities problematic. Therefore, the comparisons in this study take place only between different fields. As can be seen from Table 1, all the evaluated fields are of similar size in Finland in terms of both the number of schools and the number of degrees offered.

Four of the five authors of this article participated in the data collection, the data analysis and the writing of the evaluation reports (see Pyykkö et al., 2020a, 200b; Seppälä et al., 2020; Wallenius et al., 2020). For this study, the data sets from the different fields were combined and reanalyzed [3]. The article applies both quantitative and qualitative methods, and our approach can thus be labeled as mixed methods (see Modell, 2009).

The quantitative data of this article were collected from the part of the survey questionnaire in which the respondents were asked to rate the relevance and impact of all of the six steering mechanisms applied by the MEC. As the field-specific small groups consisted of the upper management and administration of the representative institutions and schools, their responses can be considered as expert opinions representing each of the fields' and schools' official views. The quantitative data analysis followed explorative logic (e.g. Broadbent and Guthrie, 2008). Due to the size of the data set $(n=31)$, multivariate analysis was not possible. The impact and relevance of the six steering mechanisms were thus studied by comparing their means (descriptive statistics). While no actual hypothesis was set, the logical expectation was that there would be a positive correlation between the perceived impact and relevance of each of the steering mechanisms. Spearman's rank-order correlation was used to test this. The analysis of the means and Spearman's correlation indicated interesting findings, which we further pursued through a qualitative analysis of the openended questions in the survey data.

Accordingly, the survey also contained the open-ended question: "How should the steering mechanisms be developed?," which was posed to all the respondent groups. There was a total of 30 open-ended responses out of the possible 31 to this question. Using a qualitative content analysis that can be labeled as conventional content analysis (Hsieh and Shannon, 2005), the aim of the analysis was to gain an understanding on how the field-specific small groups perceived the different steering mechanisms, their usefulness and the need to develop them from the viewpoint of different fields of science. Next, the contents of the open-ended questions were coded according to the themes emerging from the data. The themes that were most prevalent, being mentioned in at least six different responses, were then selected to be

\begin{tabular}{|c|c|c|c|c|}
\hline \multirow[b]{2}{*}{ Field of study } & \multicolumn{2}{|c|}{ Responding institutions } & \multicolumn{2}{|c|}{ Number of graduates in 2018} \\
\hline & $\begin{array}{l}\text { Total number of } \\
\text { schools }\end{array}$ & $\begin{array}{l}\text { Number of } \\
\text { responses }\end{array}$ & $\begin{array}{c}\text { Number of bachelor's } \\
\text { degrees }\end{array}$ & $\begin{array}{c}\text { Number of master's } \\
\text { degrees }\end{array}$ \\
\hline $\begin{array}{l}\text { Business and } \\
\text { economics }\end{array}$ & 10 & 10 & 1,869 & 2,145 \\
\hline Engineering & 7 & 6 & 1,722 & 2,136 \\
\hline Humanities & 8 & 8 & 1,926 & 1,666 \\
\hline Social sciences & 8 & 7 & 1,383 & 1,632 \\
\hline
\end{tabular}

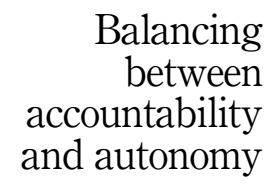

55
Table 1. Statistics in the four fields studied Vipunen (2020), Pyykkö et al. (2020a, p. 8) 
JPBAFM 34,6

\section{6}

reported in the study. These themes help to explain and deepen the understanding on the responses to the quantitative part of the survey describing the perceived impact and relevance of the steering mechanisms.

Next, we will explain how the field-specific small groups perceived the relevance of the six steering mechanisms (indicator-based funding, performance agreements between the MEC and the individual universities, project funding, strategy-based funding, the regulation of the educational responsibility of the universities and steering by information). Using both the quantitative and qualitative data, the results highlight the paradoxical tension in the steering of HEIs by demonstrating how the perceived relevance and impact of the steering instruments vary.

\section{Results of the empirical study}

\subsection{Quantitative analysis: experienced impact and relevance of the steering mechanisms}

Table 2 presents the findings, listed from highest to lowest, based on the experienced impact of the six steering mechanisms applied by the MEC. The numbers presented in Table 2 are the means based on the respondents' answers as they were asked to rate the relevance and impact of each steering mechanism on a scale of 0-100 (the value 0 stands for no relevance/impact and the value 100 for the highest possible relevance/impact). In the survey, the term "impact" was used to measure the effect that a particular steering mechanism has on the planning of the education provision within each field of science. The exact term used in the questionnaire in Finnish that we have translated in this study as "impact" refers to the effects and influence that the steering mechanism has in the long-term planning and development of each field of science. Analogously, the term "relevance" was used to measure the appropriateness, suitability and expediency that the respondents perceived each particular steering mechanism as having on the planning and development of each field of science in the long term.

Regarding the MEC's steering mechanisms, Table 2 shows that the four mechanisms tied to funding are also the ones that are perceived to have the most impact. Nevertheless, one of the steering mechanisms, namely indicator-based funding, stands out. It seems to be not just the most impactful steering mechanism but also the most controversial one. Consequently, in the case of indicator-based funding, the difference between the experienced impact and the relevance is strikingly high: -42.6 . The fact that indicator-based funding was perceived as the most impactful yet the least relevant steering mechanism entails an interesting paradox.

Unlike indicator-based funding, the rest of the steering mechanisms' correlations were logical - the higher the experienced impact of the steering mechanism was, the greater was also the experienced relevance. Accordingly, while the Spearman's rank-order correlation between the impact and relevance of the steering mechanisms was as low as 0.14 , if the

Table 2.

Means of relevance and the impact of the different steering mechanisms

\begin{tabular}{lccc}
\hline Steering mechanism & $\begin{array}{c}\text { Relevance } \\
\text { (mean) }\end{array}$ & $\begin{array}{c}\text { Impact } \\
\text { (mean) }\end{array}$ & Difference \\
\hline $\begin{array}{l}\text { Indicator-based funding } \\
\text { Performance agreements between the MEC and the }\end{array}$ & 37.6 & 80.2 & -42.6 \\
individual universities & 52.8 & 77.7 & -24.9 \\
Project funding & & & \\
Strategy-based funding & 50.0 & 60.0 & -10.0 \\
Regulation of educational responsibility of the universities & 47.5 & 59.9 & -12.4 \\
Steering by information & 47.4 & 56.7 & -9.3 \\
Mean & 43.2 & 45.7 & -2.5 \\
& 46.4 & 63.3 & -16.9 \\
\hline
\end{tabular}


indicator-based funding were to be excluded from the list, the rank-order correlation would be 1 , indicating a strong correlation.

Table 3 presents how the respondents from the four fields of science experience the relevance and impact of the MEC's steering mechanisms taken together. While the respondents in the humanities experience the least relevance (43.9), their colleagues in business and economics experience the highest relevance (50.5). Nevertheless, the difference between the two is relatively small; the same applies to the differences regarding the experienced impact.

\subsection{Qualitative analysis: understanding the logics of high impact and low relevance}

The results of the quantitative data analysis beg the question as to why the experienced impact of the MEC's steering mechanisms is higher than their experienced relevance; in addition, we ask why the experienced relevance of indicator-based funding is so low in particular? We approach the first question through qualitative data analysis, aiming to understand why the experienced impact and relevance of the different steering mechanisms vary. After this, in Section 5, we address the second question. We base our analysis on the received responses to the open-ended survey question: "How should the steering mechanisms be developed?"

A content analysis of the qualitative data suggests the following five distinct themes, which were mentioned more than six times in the data (the respective numbers after each theme refer to the number of responses in which the theme was mentioned). The responses indicated five problems in the steering of the HEIs that explain the difference between the perceived impact and relevance of the steering mechanisms and highlight the tensions in the steering of HEIs: (1) lack of predictability and long-term stability (18); (2) problems related to project funding (9); (3) lack of core funding (8); (4) problems related to quality (8); and (5) distortion problems (7). We take a closer look at these themes below.

By far, the most often mentioned problem (mentioned altogether in 18 responses) was the lack of predictability and long-term planning in the MEC's steering mechanisms. This theme was typically explicitly stated in the responses:

Higher education institutions need predictable funding; the steering mechanisms should take into account the universities' long commitment periods for their students (7 years from entry). (Respondent team from business and economics)

[There is a need for] long-termism, consistency, and predictability. (Respondent team from social sciences)

The data suggest that the MEC's steering mechanisms were typically considered to suffer from unpredictability and myopia. Thus far, the MEC has been renewing its steering mechanism (especially the means for allocating funding) often (e.g. Kallio et al., 2020) as the standard cycle of updating the funding scheme and performance agreements is four years, whereas the planned minimum time to complete both bachelor's and master's degrees is typically five years. It is likely that this causes experiences of unpredictability and makes it difficult for schools to design, plan and develop their education provision.

\begin{tabular}{lcrrr}
\hline Field of education provision & Relevance (mean) & Impact (mean) & Difference & The difference in the \\
\hline Business and economics & 50.5 & 61.5 & -11.1 & means of relevance and \\
Engineering & 48.3 & 63.7 & -15.5 & impact of the steering \\
Humanities & 43.9 & 67.3 & -23.3 & mechanisms by field of \\
Social sciences & 50.0 & 69.0 & -19.0 & science \\
\hline
\end{tabular}


JPBAFM 34,6

Another theme that was often mentioned was the problems related to project funding. These problems were typically associated with two issues in the responses. Firstly, the project funding was perceived to be disconnected from the other activities of the universities, meaning that the activities financed with the project funds might not become integrated in the university's core activities, as illustrated in the following excerpt:

Projects may lead to individual development efforts, but there is a risk that the project will be disconnected from the core activities, in which case its outcomes will die out at the end of the project. (Respondent team from the humanities)

Secondly, project funding was considered problematic because projects are temporary, and as such, they intensify the problems discussed above related to the theme of unpredictability and myopia in steering the universities. Moreover, project funding was seen to increase the administrative burden:

The steering mechanisms are too short-lived. The MEC's project funding, for example, fragments operations and causes an administrative burden. The steering should be based on the long-term goals determined by the university itself. (Respondent team from business and economics)

It is indisputable that projects cause considerable administrative burden as applying for projects, evaluating project applications and reporting on projects takes time, thus consuming labor. Consequently, several responses pleaded for core funding to replace or complement project- and performance-based funding. Hence, the lack of core funding was a theme in the data that was typically mentioned as a general root of the problems within the MEC's performance-based funding:

[There is a need for] stable core funding so that the funding is not as strongly linked to performance. Linking funding to performance does not necessarily contribute to the quality of education at the national level, but to producing quantity in the short run. (Respondent team from business and economics)

[There is a need] to get rid of MEC's projects and [performance-based] funding, and provide the university with a budget that the university can use according to the competence needs of the region [of the respective university]. (Respondent team from engineering)

In Finland, core funding, proposed here as the solution to the identified problems by the fieldspecific respondent groups, had comprised universities' primary funding method before the MEC adopted a performance-based funding scheme. Core funding operates differently compared to performance-based funding; if thought of in terms of an employment contract, the former could be seen as a monthly salary and the latter as a commission salary. The theme describing the lack of core funding in the survey data was also connected to the next theme found in the responses, namely problems related to quality in education. In the data, problems related to quality were manifested in two interconnected ways. Firstly, the MEC's steering mechanisms were considered problematic because they measured mostly quantity:

It would be important to have more qualitative indicators and more qualitative ways to measure performance. (Respondent team from engineering)

Secondly, applying PM-based steering in higher education was considered problematic from the perspective of the quality as such:

Of course, the [performance-based] funding seems like an effective way to steer, but in the end it's pretty short-sighted from an educational quality perspective. (Respondent team from engineering)

Accordingly, it is not only difficult to develop indicators that are able to capture quality aspects in higher education per se, but it is at least as difficult to define what quality means in different fields in the case of such a complicated, abstract and multifaceted phenomenon as 
higher education (Kallio and Kallio, 2014; Kallio et al., 2017, 2020). As the fields of science steered by the MEC range from theoretical physics all the way to folklore studies, it is difficult to see how "one size" could possibly fit all in terms of measuring education quality. The final problem identified in the analysis was labeled as distortion problems, meaning that the fieldspecific respondent groups felt that applying the current steering mechanisms actually distorts the education provision and thus scientific outputs in the long run.

[.. . ] The strategy-based steering of the MEC may bias the overall development of the university as it favors certain fields at the expense of others. [...] (Respondent team from the humanities)

Balancing between accountability and autonomy

$[\ldots]$ The steering mechanisms tend to pull the university-level development work in conflicting directions and [consequently] ending up in short-sighted optimization of operations due to the [MEC's] funding scheme. (Respondent team from social sciences)

As illustrated by the above excerpts, some respondent teams, especially those representing the humanities, feel that the MEC's steering mechanisms tend to favor certain fields (typically pragmatic fields, such as business and engineering) at the expense of others (such as the humanities). This causes distortion problems both at the university system level and at the level of individual universities. The distortion problem is also at least implicitly linked to the experienced lack of predictability in the MEC's steering mechanisms.

The five problems discussed above are clearly major reasons behind the fact that the experienced impact of the MEC's steering mechanisms is higher than their experienced relevance throughout. However, thus far we have only implicitly explained why the experienced relevance of indicator-based funding is so low in particular. Next, with the help of our theoretical lenses, the paradox theory and institutional complexity, we examine this important question explicitly.

\section{Understanding the tension between accountability and autonomy}

In addition to the five problems identified in the data and presented above, the analysis revealed a highly complex topic that was constantly present throughout the qualitative data, namely autonomy. The idea that the MEC's steering mechanisms interfered with the autonomy of the universities manifested sometimes as an independent theme, as in the following excerpts:

[...] Strict external steering is not justifiable from the perspective of universities' autonomy. (Respondent team from business and economics)

[It is necessary to enable] higher education institutions' autonomy in developing their education. (Respondent team from engineering)

Importantly, however, compared to the five problems discussed in Section 4, the theme of autonomy manifested differently than the other problems. Accordingly, autonomy - or, more specifically, the perceived loss of it - seems to be the actual root problem that is either explicitly or implicitly connected to the other five problems. As a root problem, loss of autonomy was highlighted by the respondents throughout the data, as illustrated by the following exemplary excerpt:

[...] Strict steering does not support the diversity of science in the best possible way and will be reflected in the education provision in the longer term. [.. .] (Respondent team from the humanities)

The above excerpt indicates that the actual paradox is not just the fact that the MEC's most impactful steering mechanism - indicator-based funding - was considered to be the least relevant one by the respondent groups. Indicator-based funding, the most controversial of the six steering mechanisms, is, in fact, just a manifestation of a wider paradox. This observation 
JPBAFM 34,6

\section{0}

Figure 2.

Institutional logics, responses to demands and paradoxes in the Finnish higher education field led us to explore the dynamics of the paradox between the universities' autonomy and the universities' accountability to the state on one hand and the paradox between the universities' autonomy and the MECs coordination mechanisms on the other. As illustrated in Figure 2, there are three logics (institutional complexity) affecting the demands imposed on the universities, as follows: constitutional logic and quasi-market logic as the two variants of the state logic as well as professional logic (see Thornton et al., 2012).

Figure 2 draws a wider picture of the Finnish higher education field from the perspective of institutional complexity and paradoxes. In their operations and reactions, the three key actors - the universities, the MEC and the state - each follow different institutional logics. The outcome, institutional complexity in the Finnish higher education sector, entails both mutually complementary and mutually contradictory demands and thus includes two types of paradoxes.

The first of the two paradoxes revolves around the simultaneous demands for autonomy and accountability, which are clearly at opposite ends of the spectrum from each other. Nevertheless, the Finnish higher education field cannot exist without both autonomy and accountability, and an attempt to eliminate either would thus lead to a dysfunctional situation. In more practical terms, the Finnish state can ensure that its own constitution (guaranteeing academic freedom and scientific independence) is upheld only by providing autonomy to the universities. Vice versa, the universities would lose the legitimacy if they were not accountable to the actor (the state) that is dictating the HEI field - the Finnish higher education system is, after all, funded by the tax revenues, and there is only a marginal number of alternative means available to fund higher education in the country. Living with this persistent paradox (cf. Schad et al., 2016) means that the state and the universities need to constantly "negotiate" ways that both autonomy and accountability can be implemented. Consequently, even though the accountability versus autonomy tension between the state and the universities is paradoxical, it is, in the end, a synergistic paradox (Smith and Tracey, 2016). This is illustrated in Figure 2 by the solid two-way arrow.

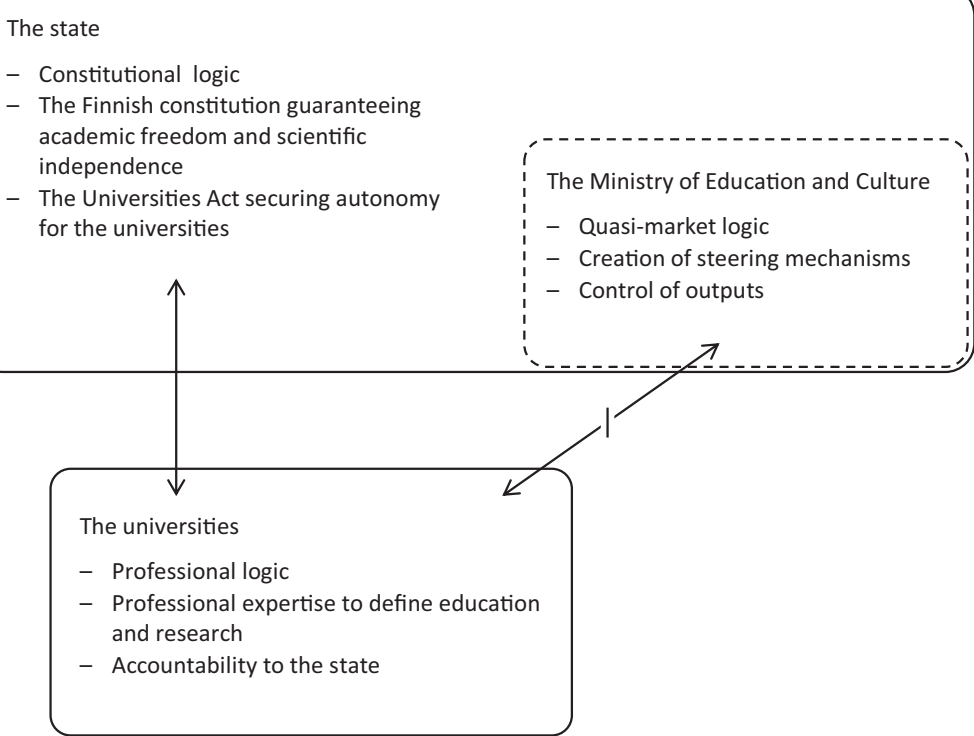


Another type of tension exists between the MEC and the universities. The role of the MEC in the state administration is to execute the allocation of funding and the coordination of educational responsibilities. In practice, this means that both creating the steering mechanisms and being in control of the universities' outputs in the state administration belong to the responsibilities of the MEC. As suggested above, the empirical analysis of this study indicates that the universities' perceived loss of autonomy is the root problem caused by the universities' external steering mechanisms. If this interpretation holds true, it also means that there is a contradictory paradox between universities' autonomy and the steering of HEIs defined by the MEC. This fact was mentioned either explicitly or implicitly in several responses in the survey.

The MEC seems to be rather self-absorbed in its steering. The universities' abilities to evaluate their own development should be trusted. [. . . ] (Respondent team from engineering)

[The MEC] should listen the universities' personnel; that is, those people that have to work according to them [the steering mechanisms]. They have the expertise to evaluate if the steering mechanisms are appropriate. (Respondent team from the humanities)

Accordingly, even though the freedom of science is secured by the Finnish constitution and the autonomy of universities is guaranteed by the Universities Act, the steering mechanisms applied by the MEC seem to undermine the universities' self-rule (Kallio et al., 2020). The outcome is a dysfunctional paradox, which is illustrated by the broken two-way arrow in Figure 2.

While the relation between the state and the MEC has not been the focus of this study; nevertheless, there seems to be a tension between the variants of the state logic that the MEC and the state are operating under. It is as if the right hand and the left hand of the public authority are not aware of each other and are pulling in different directions. This observation leads to an intriguing question as to why the MEC, being part of the state organization itself, has adopted such a perspective on accountability and further developed steering mechanisms that are, at least implicitly, in conflict with the spirit of the constitution. As Battilana and Lee (2014) suggest, a response might be that organizations exposed to different institutional logics over a relatively long time period might become hybrid organizations in which the logics they embody are not always compatible. This appears to be the case with the MEC.

Consequently, this study supports the finding made by Battilana and Lee (2014) and thus suggests that the reasons for the institutional complexity and the paradoxes lie in the cultural and historical developments. Thus, the MEC's operations are defined not just by the general state logic but also by its variant labeled in this study as quasi-market logic (Grossi et al., 2020). Moreover, one should bear in mind that even though the state institution is often perceived as a monolith in practice, it is a loosely coupled organization built around numerous autonomous ministries (12 in the Finnish case), which all have their own respective administrations, history, values, purposes and demands. From this perspective, we can conclude that the paradox related to the high impact and low relevance of the public steering mechanisms of universities becomes understandable by analyzing the history of the institutional fields involved. Therefore, we urge the scholars studying HEIs' steering mechanisms in different countries to pay more attention to the institutional evolution of the respective higher education systems. (Välimaa, 2012; Kallio et al., 2020).

\section{Conclusions and practical remarks}

We set three objectives for this study. The first of the tasks was to highlight the steering mechanisms applied in coordinating the Finnish HEIs and report their experienced impact and relevance. To do so, we studied the steering mechanisms developed by the MEC to 
JPBAFM 34,6

62

coordinate HEIs and reported on their impact and relevance as described by representatives of Finnish universities from four fields. The empirical analysis of this study showed that there is a considerable gap between the experienced impact and the experienced relevance of the ministry's steering mechanisms in higher education. At least two of the MEC's steering mechanisms, namely indicator-based funding (mean 80.2) and the performance agreements between the MEC and the individual universities (mean 77.7), seem to have a major impact on universities' operations. At the same time, none of the MEC's steering mechanisms were considered particularly relevant. The difference between the experienced relevance and impact of these two steering mechanisms was the highest (-42.6 and -24.9 , respectively) in the data. This means that even though some steering mechanisms are perceived as affecting the planning and development of certain educational fields, their relevance in steering those fields might be considered to be poor.

The second objective of the article was to gain an understanding as to why the applied steering mechanisms cause tensions for the management of HEIs. Based on the empirical analysis, we suggest that the steering mechanisms cause tension for the management of HEIs as their relevance is considered to be clearly lower than their impact. The low relevance is connected to the following five generic problems: a lack of predictability and long-term stability of the funding scheme, problems related to project funding, a lack of HEI core funding, quality problems and distortion problems. In addition, we found a root problem that was either explicitly or implicitly connected to all the other five themes. The root problem is the perceived loss of autonomy experienced by the universities. Universities face the paradoxical pressures to maintain their autonomy and to respond to the demands of the different steering mechanisms imposed on them by the state via the mandate of the MEC. Our analysis suggests that even the most impactful steering mechanisms can be considered of little relevance if they endanger universities' institutional autonomy at the same time. In this sense, it could be expected that if steering mechanisms are to be perceived as simultaneously impactful and relevant by professionals, they should be able to take into account both the demands on accountability and autonomy at the same time. As suggested by de Boer et al. (2015), the conditional funding mechanisms stand in contrast to lump-sum funding (core funding), which is seen to fit institutional autonomy best. The authors pinpoint that there is a tension between performance funding schemes and institutional autonomy, concluding that the room left to the universities to make their own decisions and trade-offs, as well as to affect the depth and scope of the agreements, is crucial. This means that the greater the level of detail the steering instruments have, the more they will intrude on the universities' autonomy. Based on our findings in this study, this holds true.

The third objective of the article was to provide practical insights into how to develop the public steering of universities. Based on our analysis, we provide three suggestions. First, our empirical data suggest that the predictability and farsightedness in applying steering mechanisms via the stability of funding instruments should be a high priority in regard to HEI steering. Accordingly, the frequency of renewing steering mechanisms, especially those that involve the allocation of public funding, should not fluctuate. Improving the predictability and farsightedness of the funding scheme should also mitigate the identified problems related to quality and distortion.

Second, as universities' missions include functions connected to national education policy goals, such as the responsibility to educate certain volumes in designed fields, long-term predictability for the universities' operations needs to be assured. Therefore, it would be advisable for the universities' basic funding to be secured so that it does not fluctuate according to (short-term) performance. The paradox of fluctuating amounts of basic funding and the need for scientific and educational stability brings tensions to the steering of HEIs.

Third, the steering mechanisms, in general, and indicator-based funding, in particular, are in many ways difficult to design; not only is it necessary to take into account several 
stakeholders' needs, but they should not cause quality and distortion problems, either. Even though the formulation of Finnish higher education policy and steering has, in general, been relatively inclusive to consider various stakeholder perspectives, our analysis indicates that when next renewing the performance-based funding scheme, finding an acceptable balance between accountability and institutional autonomy should be a key objective. Only through adequate autonomy can universities ensure that the education they offer remains of high quality and does not become distorted.

Our study contributes to earlier literature by, first, highlighting the tensions between autonomy and accountability in performance-based steering models of public sector organizations and, second, by explaining them through the lenses of institutional complexity and the paradox theory. As suggested by Grossi et al. (2020), diverging logics can coexist in a university context but can still be quite separate and not fully blended. In a similar vein, our study concludes that, in Finland, the state logic with its two variants (constitutional and quasi-market logic) and the professional logic coexist yet still creating a paradox since they are all affected by different demands. As suggested by Smith and Tracey (2016), rather than trying to resolve the competing demands, paradox theory pursues ways to cope with them and potentially even develop positive outcomes. One way to do this is to try to make the performance agreements and performance funding schemes truly joint efforts between the MEC and the universities, where both parties can express their interests on a limited number of issues, thereby leaving the universities some room on how to approach them, as suggested by de Boer et al. (2015). Based on our study, we conclude that attention should be paid to the competing and paradoxical tensions created by the multitude of operating logics of the performance-based steering of universities. Therefore, accountability and autonomy should be better balanced when designing performance-based funding schemes for universities.

\section{Notes}

1. Although the FINEEC's survey reported in this study was explicitly targeted only to the education provision of the universities, many respondents might have had the whole funding model in mind.

2. However, representatives of one faculty/school did not respond to all the questions, meaning that the exact number of responses ranged from 28 to 31 .

3. Even though the empirics of this article are based on the data of the FINEEC's evaluations, the data set, the empirical analysis and the findings presented in this article have never been published.

\section{References}

Aarrevaara, T. (2010), "Academic freedom in a changing academic world", European Review, Vol. 18 No. 1 , pp. 55-69.

Agyemang, G. and Broadbent, J. (2015), "Management control systems and research management in universities: an empirical and conceptual exploration", Accounting, Auditing and Accountability Journal, Vol. 28 No. 7, pp. 1018-1046.

Ahonen, P. and Koljonen, J. (2020), "The contents of the National Audit Office of Finland performance audits, 2001-2016. An interpretive study with computational content analysis", Journal of Public Budgeting, Accounting and Financial Management, Vol. 32 No. 1, pp. 49-66.

Ahrens, T. and Khalifa, R. (2015), "The impact of regulation on management control: compliance as a strategic response to institutional logics of university accreditation", Qualitative Research in Accounting and Management, Vol. 12 No. 2, pp. 106-126.

Alajoutsijärvi, K., Juusola, K. and Lamberg, J. (2014), "Institutional logic of business bubbles: lessons from the Dubai business school mania", Academy of Management Learning and Education, Vol. 13 No. 1, pp. 5-25. 
JPBAFM 34,6

64
Alvesson, M., Gabriel, Y. and Paulsen, R. (2017), Return to Meaning: A Social Science with Something to Say, Oxford University Press, Oxford.

Battilana, J. and Lee, M. (2014), "Advancing research on hybrid organizing: insights from the study of social enterprises", Academy of Management Annals, Vol. 8 No. 1, pp. 397-441.

Bennetot-Pruvot, E. and Estermann, T. (2017), University Autonomy in Europe III. The Scorecard 2017, European University Association, Brussels.

Besharow, M.L. and Smith, W.K. (2014), "Multiple institutional logics in organizations: explaining their varied nature and implications", Academy of Management Review, Vol. 39 No. 3, pp. 364-381.

Boitier, M. and Rivière, A. (2013), "Freedom and responsibility for French universities: from global steering to local management", Accounting, Auditing and Accountability Journal, Vol. 26 No. 4, pp. 616-649.

Broadbent, J. (2007), “If you can't measure it, how can you manage it? Management and governance in higher educational institutions", Public Money and Management, Vol. 27 No. 3, pp. 193-198.

Broadbent, J. and Guthrie, J. (2008), "Public sector to public services: 20 years of contextual accounting research", Accounting, Auditing and Accountability Journal, Vol. 21 No. 2, pp. 129-169.

Brown, R. (Ed.) (2010), Higher Education and the Market, Routledge, Abingdon.

Chandler, J. (2008), "Academics as professionals or managers? A textual analysis of interview data", Qualitative Research in Accounting and Management, Vol. 5 No. 1, pp. 48-63.

Claeys-Kulik, A.-L. and Estermann, T. (2015), DEFINE Thematic Report: Performance-Based Funding of Universities in Europe, European University Association, Brussels.

Craig, R., Amernic, J. and Tourish, D. (2014), "Perverse audit culture and accountability of the modern public university", Financial Accountability and Management, Vol. 30 No. 1, pp. 1-24.

Czarniawska, B. (2019), "Mergers and acquisitions: the latest university fashion?", Qualitative Research in Accounting and Management, Vol. 17 No. 1, pp. 18-32.

de Boer, H., Jongbloed, B., Benneworth, P., Cremonini, L., Kolster, R., Kottmann, A., Lemmens-Krug, K. and Vossensteyn, H. (2015), Performance-based Funding and Performance Agreements in Fourteen Higher Education Systems, Report for the Ministry of Education, Culture and Science, Center for Higher Education Policy Studies (CHEPS), Enschede, The Netherlands.

Decree of the MEC Clarifying the Educational Responsibilities of Universities 1451/2014”, Finnish at: available at: https://www.finlex.fi/fi/laki/alkup/2014/20141451 (accessed 10 June 2021).

Dobija, D., Górska, A.M. and Pikos, A. (2019), "The impact of accreditation agencies and other powerful stakeholders on the performance measurement in Polish universities", Baltic Journal of Management, Vol. 14 No. 1, pp. 84-102.

Enders, J., de Boer, H. and Weyer, H. (2013), "Regulatory autonomy and performance: the reform of higher education re-visited", Higher Education, Vol. 65 No. 1, pp. 5-23.

Exworthy, M., Powell, M. and Mohan, J. (1999), "Markets, bureaucracy and public management: the NHS: quasi-market, quasi-hierarchy and quasi-network?", Public Money and Management, Vol. 19 No. 4, pp. 15-22.

Fairhurst, G.T., Smith, W.K., Banghart, S.G., Lewis, M.W., Putnam, L.L., Raisch, S. and Schad, J. (2016), "Diverging and converging: integrative insights on a paradox meta-perspective", Academy of Management Annals, Vol. 10 No. 1, pp. 173-182.

Feiock, R.C. (2002), “A quasi-market framework for development competition”, Journal of Urban Affairs, Vol. 24 No. 2, pp. 123-142.

Ferlie, E., Musselin, C. and Andresani, L. (2009), “The 'steering' of higher education systems: a public management perspective", in Paradeise, C., Reale, E., Bleikle, I. and Ferlie, E. (Eds), University Governance: Western European Perspectives, Springer, pp. 1-20.

Gebreiter, F. and Hidayah, N. (2019), "Individual responses to competing accountability pressures in hybrid organisations", Accounting, Auditing and Accountability Journal, Vol. 32 No. 3, pp. 727-749. 
Government Decree on University Degrees (2004), 794/2004, available in Finnish at: https://www. finlex.fi/fi/laki/kaannokset/2004/en20040794.pdf.

Greenwood, R., Raynard, M., Kodeih, F., Micelotta, E.R. and Lounsbury, M. (2011), "Institutional complexity and organizational responses", Academy of Management Annals, Vol. 5 No. 1, pp. 317-371.

Grossi, G., Kallio, K.-M., Sargiacomo, M. and Skoog, M. (2019), “Accounting, performance management systems and accountability changes in knowledge-intensive public organizations: a literature review and research agenda", Accounting, Auditing and Accountability Journal, Vol. 33 No. 1, pp. 256-280.

Grossi, G., Dobija, D. and Strzelczyk, W. (2020), "The impact of competing institutional pressures and logics on the use of performance measurement in hybrid universities", Public Performance and Management Review, Vol. 43 No. 4, pp. 818-844.

Guthrie, J. and Neumann, R. (2007), "Economic and non-financial performance indicators in universities", Public Management Review, Vol. 9 No. 2, pp. 231-252.

Harun, H., Wardhaningtyas, S., Khan, H.Z., An, Y. and Masdar, R. (2020), "Understanding the institutional challenges and impacts of higher education reforms in Indonesia”, Public Money and Management, Vol. 40 No. 4, pp. 307-315.

Hood, C. (1995), "Emerging issues in public administration", Public Administration, Vol. 73 No. 1, pp. 165-183.

Hsieh, H.F. and Shannon, S.E. (2005), "Three approaches to qualitative content analysis”, Qualitative Health Research, Vol. 15 No. 9, pp. 1277-1288.

Iacuzzi, S., Garlatti, A., Fedele, P. and Lombrano, A. (2020), "Integrated reporting and change: evidence from public universities", Journal of Public Budgeting, Accounting and Financial Management, Vol. 32 No. 2, pp. 291-310.

Järvenpää, M., Kallio, K.M., Kallio, T.J. and Rautiainen, A. (2021), "The chain of control in resultsbased management in Finnish universities", in Hoque, Z. (Ed.), Public Sector Reform and Performance Management in Developed Economies: Outcomes-Based Approaches in Practice, Routledge, London, New York, NY, pp. 177-192.

Juusola, K., Kettunen, K. and Alajoutsijärvi, K. (2015), "Accelerating the Americanization of management education: five responses from business schools", Journal of Management Inquiry, Vol. 24 No. 4, pp. 347-369.

Kallio, K.M. and Kallio, T.J. (2014), "Management-by-results and performance measurement in universities - implications for work motivation”, Studies in Higher Education, Vol. 39 No. 4, pp. 574-589.

Kallio, K.M., Kallio, T.J., Tienari, J. and Hyvönen, T. (2016), "Ethos at stake: performance management and academic work in universities", Human Relations, Vol. 69 No. 3, pp. 685-709.

Kallio, K.M., Kallio, T.J. and Grossi, G. (2017), "Performance measurement in universities: ambiguities in the use of quality vs quantity in performance indicators", Public Money and Management, Vol. 37 No. 4, pp. 293-300.

Kallio, T.J., Kallio, K.M. and Blomberg, A. (2020), "From professional bureaucracy to competitive bureaucracy - redefining universities' organizational principles, performance measurement criteria, and reason for being", Qualitative Research in Accounting and Management, Vol. 17 No. 1, pp. 82-108.

Kallio, K.M., Kallio, T.J., Grossi, G. and Engblom, J. (2021), "Institutional logic and scholars' reactions to performance measurement in universities", Accounting, Auditing and Accountability Journal, Vol. 34 No. 9, pp. 104-130.

Kallunki, J., Kivistö, J. and Kohtamäki, V. (2019), "Funding of higher education (Finland)", in Kauko, J. and Jacob, W.J. (Eds), Bloomsbury Education and Childhood Studies, Bloomsbury Academic, London, available at: https://www.becs-bloomsbury.com/article?docid=b-9781474209489\&tocid=b9781474209489-016 (accessed 10 June 2021). 
JPBAFM 34,6

Karran, T. (2009), "Academic freedom: in justification of a universal ideal", Studies in Higher Education, Vol. 4 No. 3, pp. 263-283.

Kivistö, J., Pekkola, E. and Lyytinen, A. (2017), "The influence of performance-based management on teaching and research performance of Finnish senior academics", Tertiary Education and Management, Vol. 23 No. 3, pp. 260-275.

Kivistö, J., Pekkola, E., Nordstrand Berg, L., Hansen, H.F., Geschwind, L. and Lyytinen, A. (2019), "Performance in higher education institutions and its variations in Nordic policy", in Pinheiro, R., Geschwind, L., Foss Hansen, H. and Pulkkinen, K. (Eds), Reforms, Organizational Change and Performance in Higher Education: A Comparative Account from the Nordic Countries, Palgrave Macmillan, Cham, pp. 37-67.

Komutputipong, N. and Keerasuntonpong, P. (2019), "Accountability perception of Thai Government: to whom and what counts", Journal of Public Budgeting, Accounting and Financial Management, Vol. 31 No. 1, pp. 45-65.

Lane, J. (2010), "Let's make science metrics more scientific", Nature, Vol. 464 No. 7288, pp. 488-489.

Mah'd, O. (2020), "Bottom-up rather than top-down: evidence from Middle eastern and north African educational institutions", Journal of Public Budgeting, Accounting and Financial Management, Vol. 32 No. 4, pp. 671-690.

Mampaey, J. and Huisman, J. (2015), "Defensive stakeholder management in European universities: an institutional logics perspective", Studies in Higher Education, Vol. 41 No. 12, pp. 2218-2231.

Marginson, S. (2013), "The impossibility of capitalist market in higher education", Journal of Educational Policy, Vol. 28 No. 3, pp. 353-370.

MEC (Ministry of Education and Culture) (2019), "Development of higher education", available at: https://minedu.fi/en/development-of-higher-education (accessed 12 February 2021).

MEC (Ministry of Education and Culture) (2021), "Steering, financing and agreements of higher education institutions, science agencies and research institutes", available at: https://minedu.fi/ en/steering-financing-and-agreements (accessed 26 January 2021).

Melin, G., Zuijdam, F., Good, B., Angelis, J., Enberg, J., Fikkers, D.J., Puukka, J., Swenning, A.K., Kosk, K., Lastunen, J. and Zegel, S. (2015), "Towards a future proof system for higher education and research in Finland", Reports of the Ministry of Education and Culture, Finland 2015:11, available at: http://urn.fi/URN:ISBN:978-952-263-349-1 (accessed 10 June 2021).

Miller, P. (1998), "The margins of accounting”, The European Accounting Review, Vol. 7 No. 4, pp. $605-621$.

Mingers, J. and Willmott, H. (2013), “Taylorizing business school research: on the 'one best way' performative effects of journal ranking lists”, Human Relations, Vol. 66 No. 8, pp. 1051-1073.

Mkasiwa, T.A. (2020), "Budgetary practices in a Tanzanian University: Bourdieu's theory", Journal of Public Budgeting, Accounting and Financial Management, Vol. 32 No. 3, pp. 399-420.

Modell, S. (2009), "In defense of triangulation: a critical realist approach to mixed methods research in management accounting", Management Accounting Research, Vol. 20 No. 3, pp. 208-221.

Modell, S. (2019), "Constructing institutional performance: a multi-level framing perspective on performance measurement and management", Accounting and Business Research, Vol. 49 No. 4, pp. $428-453$.

Northcott, D. and Linacre, S. (2010), "Producing spaces for academic discourse: the impact of research assessment exercises and journal quality rankings", Australian Accounting Review, Vol. 20 No. 1 , pp. 38-54.

OECD (2017), OECD Reviews of Innovation Policy: Finland 2017, OECD Publishing, Paris. doi: 10.1787/ 9789264276369-en (accessed 10 June 2021).

OECD (2019), Education at a Glance, OECD Publishing, Paris. doi: 10.1787/f8d7880d-en (accessed 10 June 2021). 
Owal Group (2016), Yliopistolakiuudistuksen Vaikutusten Arviointi, Opetus- Ja Kulttuuriministeriön Julkaisuja 30, [Impact Evaluation of the Universities Act Reform], Publications of the Ministry of Education and Culture, Helsinki, available at: http://urn.fi/URN:ISBN:978-952-263-420-7 (accessed 10 June 2021).

Pache, A.-C. and Santos, F. (2013), "Inside the hybrid organization: selective coupling as a response to competing institutional logics", Academy of Management Journal, Vol. 56 No. 4, pp. 972-1001.

Parker, L.D. (2002), "It's been a pleasure doing business with you: a strategic analysis and critique of university change management”, Critical Perspectives on Accounting, Vol. 13 Nos 5-6, pp. 603-619.

Parker, L. and Guthrie, J. (2010), "Business schools in an age of globalization", Accounting, Auditing and Accountability Journal, Vol. 23 No. 1, pp. 5-13.

Pekkola, E. and Kivistö, J. (2019a), "Management, leadership, and governance in higher education (Finland)", in Kauko, J. and Jacob, W.J. (Eds), Bloomsbury Education and Childhood Studies, Bloomsbury Academic, London. doi: 10.5040/9781350995925.0015 (accessed 10 June 2021).

Pekkola, E. and Kivistö, J. (2019b), "Government, policy, and the role of the state in higher education (Finland)", in Kauko, J. and Jacob, W.J. (Eds), Bloomsbury Education and Childhood Studies, Bloomsbury Academic, London. doi: 10.5040/9781350995925.0014 (accessed 10 June 2021).

Pettersen, I. (2015), "From metrics to knowledge? Quality assessment in higher education", Financial Accountability and Management, Vol. 31 No. 1, pp. 23-40.

Pidd, M. and Broadbent, J. (2015), "Business and management studies in the 2014 research excellence framework", British Journal of Management, Vol. 26 No. 4, pp. 569-581.

Piiroinen, O. (2013), "The transnational idea of university autonomy and the reform of the Finnish Universities Act”, Higher Education Policy, Vol. 26 No. 1, pp. 127-146.

Pinheiro, R., Geschwind, L., Foss Hansen, H. and Pulkkinen, K. (Eds) (2019), Reforms, Organizational Change and Performance in Higher Education: A Comparative Account from the Nordic Countries, Palgrave Macmillan.

Pirttilä, A., Silvén, O., Harrikari, H., Joukkola, E., Juvonen, L., Kontio, J., Rehn, A. and Leppänen, O. (2020), Tekniikan korkeakoulutuksen arviointi, Kansallinen koulutuksen arviointikeskus, Julkaisut 3, Tampere.

Pollitt, C. and Bouckaert, G. (2004), Public Management Reform: Comparative Analysis, 2nd ed., Oxford University Books, Oxford.

Pyykkö, R., Vuorio-Lehti, M. and Vuorinen, B. (2019), "Government key projects (GKP) as a tool for the development of learning and teaching in Finnish universities", International Journal of Learning, Teaching and Educational Research, Vol. 18 No. 13, pp. 150-170.

Pyykkö, R., Kivistö, J., Pirttilä, A., Wallenius, J., Huusko, M., Leppänen, O., Mustonen, K. and Nordblad, M. (2020a), Entering Working Life with a High Level of Competence Evaluations of Higher Education in Humanities, Business, Technology and Social Sciences, Finnish Education Evaluation Centre, Summaries 3, Tampere.

Pyykkö, R., Tolonen, M., Levä, K., Mahlamäki-Kultanen, S., Pantermöller, M., Pettersson, T., Saarinen, S. and Huusko, M. (2020b), Humanistisen alan korkeakoulutuksen arviointi, Kansallinen koulutuksen arviointikeskus, Julkaisuja 1, Tampere.

Reay, T. and Hinings, C.R. (2005), "The recomposition of an organizational field: health care in Alberta”, Organization Studies, Vol. 26 No. 3, pp. 349-382.

Schad, J., Lewis, M.W., Raisch, S. and Smith, W.K. (2016), "Paradox research in management science: looking back to move forward", Academy of Management Annals, Vol. 10 No. 1, pp. 5-64.

Seppälä, U., Kivistö, J., Joas, M., Kaikkonen, V., Rantanen, T., Rantanen, T., Tiilikainen, T. and Nordblad, M. (2020), Yhteiskuntatieteellisen korkeakoulutuksen arviointi, Kansallinen koulutuksen arviointikeskus, Julkaisuja 2, Tampere.

Shore, C. (2008), "Audit culture and illiberal governance: universities and the politics of accountability", Anthropological Theory, Vol. 8 No. 3, pp. 278-298.
Balancing between accountability and autonomy 
JPBAFM 34,6

68

Siekkinen, T., Pekkola, E. and Carvalho, T. (2020), "Change and continuity in the academic profession: Finnish universities as living labs", Higher Education, Vol. 79 No. 3, pp. 533-551.

Siltaloppi, J., Laurila, J. and Artto, K. (2019), "In the service of a higher good: resilience of academics under managerial control”, Organization. doi: 10.1177/1350508419890084.

Smith, W.K. and Tracey, P. (2016), "Institutional complexity and paradox theory: complementarities of competing demands", Strategic Organization, Vol. 14 No. 4, pp. 455-466.

Suomi, K., Kuoppakangas, P., Hytti, U., Hampden-Turner, C. and Kangaslahti, J. (2014), "Focusing on dilemmas challenging reputation management in higher education", International Journal of Educational Management, Vol. 28 No. 4, pp. 461-478.

ter Bogt, H.J. and Scapens, R.W. (2012), "Performance management in universities: effects of the transition to more quantitative measurement systems", European Accounting Review, Vol. 21 No. 3, pp. 451-497.

Thornton, P.H., Ocasio, W. and Lounsbury, M. (2012), The Institutional Logics Perspective: A New Approach to Culture, Structure, and Process, Oxford University Press, Oxford.

Tourish, D. and Willmott, H. (2015), "In defiance of folly: journal rankings, mindless measures and the ABS guide", Critical Perspectives on Accounting, Vol. 26 No. 1, pp. 37-46.

Tourish, D., Craig, R. and Amernic, J. (2017), "A mania for assessment: how an audit culture undermines the purpose of universities", in Huzzard, T., Benner, M. and Kärreman, D. (Eds), The Corporatization of the Business School: Minerva Meets the Market, Routledge, Abingdon, pp. 34-55.

Upping, P. and Oliver, J. (2012), "Thai public universities: modernisation of accounting practices", Journal of Accounting and Organizational Change, Vol. 8 No. 3, pp. 403-430.

Välimaa, J. (2012), "The corporatization of national universities in Finland”, in Pusser, B., Kempner, K., Marginson, S. and Ordorika, I. (Eds), Universities and the Public Sphere: Knowledge Creation and State Building in the Era of Globalization, Routledge, Abingdon, pp. 101-119.

Vakkuri, J. (2010), "Struggling with ambiguity: public managers as users of NPM-oriented management instruments", Public Administration, Vol. 88 No. 4, pp. 999-1024.

Verhoest, K., Peters, B.G., Bouckaert, G. and Verschuere, B. (2004), "The study of organisational autonomy: a conceptual review", Public Administration and Development, Vol. 24 No. 2, pp. 101-118.

Vipunen - Education Statistics Finland (2020), available at: https://vipunen.fi/en-gb (accessed 26 January 2021).

Wallenius, J., Ojasalo, K., Friman, M., Hallikainen, M., Kallio, T.J., Sandström, J., Tuuliainen, M. and Mustonen, K. (2020), Kauppatieteiden ja liketalouden korkeakoulutuksen arviointi, Kansallinen koulutuksen arviointikeskus, Julkaisuja 4, Tampere.

\section{Corresponding author}

Kirsi-Mari Kallio can be contacted at: kirsi-mari.kallio@utu.fi

For instructions on how to order reprints of this article, please visit our website:

www.emeraldgrouppublishing.com/licensing/reprints.htm

Or contact us for further details: permissions@emeraldinsight.com 